Türem, Z. U., \& Ballestero, A. (2014). Regulatory Translations: Expertise and Affect in Global Legal Fields. Indiana Journal of Global Legal Studies, 21(1), 1-25.

\title{
Regulatory Translations: Expertise and Affect in Global Legal Fields
}

\author{
Ziya Umut Türem, Boğaziçi University \\ Andrea Ballestero, Rice University [ORCID: 0000-0001-7692-0514]
}

"The biggest chunk of my job involves translation; I am, for all intents and purposes, a translator," said Arif Asya, a Turkish corporate lawyer who was part of a roundtable in the Regulatory Translations workshop we held in Istanbul in May 2013. Being a corporate lawyer and working for foreign clients, as well as local ones, he argued, put him in situations where he had to actively engage in cultural and linguistic translations. At times, he needed to translate the business context and local sensitivities to a foreign client, a process that included, in his words, "selective translations," which effectively meant nontranslations. Sometimes, he needed to translate local laws to local clients because such laws, having been distilled not only from Ottoman and Turkish history, but also from Roman and German law, contained quite arcane language. Asya's intervention as a practicing corporate lawyer-translator in an otherwise academic setting was a powerful reminder that as scholars we also, to some extent, are engaged in constant processes of translation. For in the workshop where earlier versions of the papers in this collection were presented, participants not only used the concept of "translation" as an analytic in their respective projects, but also performed constant translation-work, as we all came from rather diverse academic and professional backgrounds, ranging from [End Page 1] law to anthropology, accounting to political science, or nongovernmental organization (NGO) work to corporate law firms.

Building on that experience, the workshop in Istanbul and this special issue attempt to mobilize "translation" as a heuristic to observe, understand, and explain regulatory circulations. Our goal has been to work with translation as a lens through which we can analyze the politics of legal and regulatory change in different parts of the globe at different temporalities. In this introduction, we attempt to show the potential that joining the two concepts, regulation and translation, offers 
for critical reflection, particularly for those interested in questions of legality, normativity, and "the publics" of such legal-regulatory ordering.

As Asya's comment so powerfully conveys, translation has become a ubiquitous idiom for legal practitioners, citizens, and academics reflecting on how these actors engage in global relations, legal interactions, and political networks. As a concept that so firmly grasps the imagination and practice of both subjects and objects of social scientific research, translation offers a productive window to analyze the politics of law and regulation and the sharing of technical questions, theoretical resources, and practical concerns between social commentators and practitioners. In a world of burgeoning expert regimes where legal actors are becoming increasingly reflexive about their knowledge practices, translation as a theoretical resource and practical concern poses interesting analytic challenges to socio-legal scholarship. It makes the distinction between legal and nonlegal actors more difficult to maintain, it brings highly technical issues into the framework of the law, and it brings into conversation geographical and cultural differences that in the past seemed difficult to put side by side. In this context of a broad base of legal subjectivities, expanded technical domains, and rediscovered difference, it is necessary to ask what specifically can we gain from utilizing the concept of translation, not just as a means to make sense of global legal flows after the 1980s, but as an enduring analytic category. The papers in this special issue offer their own answers to this question, but in this introduction, you will find a general reflection on what we, the editors, see as the collective contribution the papers make.

Through the historical richness that the authors examine, this collection offers not only powerful examples of how historical and geographical specificity matter for any attempt to adopt or change regulatory instruments, but also provides insights on how such historical differences enact various regulatory ontologies. Here, to state the obvious, we consider translation not merely as an interlingual practice. While that dimension is certainly present in some of the [End Page 2] articles ahead, the authors use the concept of translation in several different senses. Broadly speaking, translation refers to conversions of meanings and practices across different national jurisdictions, regimes of value, technical languages, and affective registers. Translations occur, too, when nature or different scales of human activity are constituted as sites for economic, scientific, or social regulation. Instead of attempting to settle the definitional difficulties with translation as a concept and practice, the variety of arguments in this collection compel us to embrace translation's ambiguous character as analytic category and practical concern. We thus sidestep any attempt to chart the concepts of translation the authors work with in favor of focusing on some of the perhaps unexpected dimensions of socio-legal life that they highlight. Instead of attempting to settle the question of what translation is, we tackle the issue of what translation, as a concept and practice, does in the world. The rest of this introduction sets the stage to explore this question by first focusing on regulation and translation as simultaneously long-standing and new objects of investigation. Next, while introducing the papers, we discuss four entry points to the social and historical domains that translation seems to activate both in the world and in our own analyses of it: time, technicality, layers, and politics/ethics. We then conclude with a short reflection on the implications of this approach. 


\section{Setting the Stage}

"Regulation," as a distinct technology of governance and knowledge production, has exploded in recent decades. David Levi-Faur and Jacint Jordana write that "[i]n recent decades, regulatory reforms have spread around the globe, accompanied by new institutions, technologies, and instruments of regulation that have had an enormous impact on the social and economic fabric."2 "The era of neoliberalism," they continue, "is also the golden era of regulation." 3 Part of the reason for this proliferation is the apparent ease with which regulations travel across the globe as seemingly fluid and flexible instruments of rule. Such recent increases in the use of regulation set the background of our interest in the concept, but we do not stop with this historical diagnosis. The articles ahead are concerned with regulation as a set of precepts and practices that potentially avoid the metaphysical commitments that [End Page 3] a monolithic conception of legality (as "the law") often brings to the table. Regulation, while providing insights as to the articulation of normative, legal, and functional logics with territories and publics, does not carry the monolithic baggage we associate with the law when studied in the singular. This practical and ideological flexibility makes regulation an analytic category with the potential of generating fresh understandings of rules and their politics in an already neoliberalized world. As Robert Baldwin, Martin Cave, and Martin Lodge suggest, "by [now], the claim that we are living in an age of the 'regulatory state' ha[s] become widely accepted as the R-word ha[s] penetrated ever more social domains across countries." ${ }^{4}$ Not surprisingly, academic interest in the topic has also increased substantially, and "[r]egulation has become a matter of topical debate in a way that it was not even a single decade ago.",

Despite this proliferation, a shared and widely accepted understanding of regulation is still pending. Bronwen Morgan and Karen Yeung suggest that "[r]egulation is ... notoriously difficult to define with clarity and precision, as its meaning and the scope of its inquiry are unsettled and contested." This definitional ambiguity, we argue, is precisely what makes regulation a legal technology of ideological and pragmatic choice in our neoliberal conjuncture. Presented as a tool that is flexible, adaptable, and ultimately transportable, regulation appears as the ultimate mechanism for the movement of norms and rules in a globalized world that is constructed upon normative assumptions of flexibility, ${ }^{7}$ liquidity ${ }^{8}$ networks, and [End Page 4] circulations. ${ }^{9}$ Due to this supposed intrinsic flexibility as a tool, regulation appears to be particularly suited for the interstices between the domestic and international fields of rulemaking and enforcement, as well as for the continuum of public and private systems of authority through which networks and fluidity can take form. ${ }^{10}$ But the rise of regulation also requires one to ask how this "elective affinity" 11 between regulatory tools and the deepening of transnational circuits of capital acquires concrete forms in specific places around the world.

As Kanishka Jayasuriya notes, globalization transforms the ways in which power is exercised through a "corresponding transformation in the architecture of the state towards a regulatory form of governance." 12 Anne-Marie Slaughter similarly suggests that even though "[s]tates still exist ... they are "disaggregated." 13 Such disaggregation arises, writes Slaughter, out of the necessities of a "world of global markets" where governments must also have a global reach to deal with "global travel ... global information networks ... and looming environmental disasters of global magnitude." ${ }^{14}$ Such reach is only possible if "[governments] relate to each other not only through the Foreign Office, but also through regulatory, judicial, and legislative 
channels." ${ }^{\prime 15}$ But parallel to this question of the endurance or debilitation of the nation-state amid different global processes, there needs to be an empirical investigation of the concrete actors that perform the lending and borrowing, importing, adapting, and globalizing of regulatory tools that allow governments to have the "desired" supranational reach Slaughter argues for and the particular architecture that Jayasuriya diagnoses. Attention to these actors and their routines, beyond statements about [End Page 5] the survival of the nation-state, reveals a rich landscape of legal formations, expert knowledge regimes, and affective commitments.

If we take as a starting point the transformation of the state's architecture through regulatory techniques, merely focusing on its weakening or strengthening in a globalized context ceases to produce generative insights about the new experimental forms legality and governance might take. In other words, if we accept, on the one hand, that part of the reason why regulation becomes of interest is that it enables, and is enabled by, global circulations and networks, and if, on the other hand, we are interested in an empirical exploration of how those enabling conditions are set in place, how can we study regulatory movements without circumscribing our findings to the question of whether the nation-state is strengthened or weakened in the process?

Furthermore, how do we avoid fetishizing the circulating norms or being completely taken over by the celebratory or dismissive discourse produced by the actors involved in managing such circulations? The first part of the answer to these questions resides in legal history. Rather than presuming that the increase in regulatory governance is an epochal watershed, we argue for keeping in sight the wealth of scholarly fields that have grappled with historic circulations of laws and norms. The (sub)field of "law and development," 16 studies on "legal transplants," 17 and the critical works in the field of "comparative law"18 have provided significant insights as to how laws and legal institutions have been circulating since at least the seventeenth century. Notions of liminality, ${ }^{19}$ vernacularization, ${ }^{20}$ and indigenization ${ }^{21}$ have helped us make sense of these cross-national and cross-level circulations and have [End Page 6] provided enough historical depth to prevent us from making claims of unprecedented change without taking for granted the historical uniqueness of our times.

The second part of the answer returns to the issue of regulation in contrast with "law." As noted earlier, studying the specificity of regulatory regimes has the advantage of directing our attention to a complex system of rules whose legality is more often than not assessed in terms of its technicality and only subsidiarily in terms of metaphysical legal concerns such as justice and legitimacy. More concretely, the vernacular understanding of regulation brings to mind contradicting rules, networks of norms that are difficult to navigate, and technical languages belonging to social arenas such as agriculture, medicine, economics, engineering, environmental science, welfare, and an almost endless number of areas of globally inflected fields. From this point of view, regulation often feels more technical and broader than law, especially when one attends to the latter's metaphysic gestures toward abstract notions of justice, balance, and authority.

Channeling questions of legal regulation through agricultural norms, benefit-sharing agreements, notions of environmental harm, competition in the marketplace, and accounting standardsalongside foundational legal questions about national borders of constitutional space-regulation seems to have the capacity to openly embrace the nitty-gritty of technicality while selectively and sporadically invoking a metaphysics of law to back up its authority and legitimacy. This 
peculiar relation between technicality and metaphysical invocations gives regulatory frameworks a hybrid character: legal to the extent that they are formally recognized as such and technical to the extent that their subject matter determines their character and reach. In other words, regulation has the capacity to recognize as intrinsically legal questions that, from a more narrow perspective, could be excluded from the realm of law and left to the realm of commerce, science, or personal choice.

Finally, the question of how to study regulatory circulations without merely zooming into the weakness or strength of the state in the global scene can be answered by thinking more carefully about the act of translation as an act of meaning creation, rather than as a mere transmission, transplantation, or adaptation of legal technologies. In part because translation is supposed to create equivalences, critical scholars often focus on the violence those equivalences do to a world that is intrinsically multiple. Yet, a more open investigation of [End Page 7] translation highlights its capacity to make associations proliferate, ${ }^{22}$ as well as its capacity to articulate inherent multiplicities that can never be reduced. ${ }^{23}$ In this collection, we examine translation with a critical openness to its productivities as a nondeterministic act of meaning and value creation. This critical openness is manifested in a careful consideration of the productivities of translation beyond claims of homogenization while not losing sight of the violence that the very attempts at regulatory standardization perform.

To engage with translation as an open concept, we begin by asking where the demand for moving legal tools and meanings across domains, regulatory and otherwise, comes from. The need to move concepts arises when difference becomes a concern, that is, when we encounter distinct legal cultures and jurisdictional and value regimes that interrupt the movement of otherwise naturalized concepts, assumptions, and socio-legal practices. This happens, for instance, when the German legal regime of "representative environmental action" starts to seem too peculiar to automatically accommodate European Union regulations and U.N. conventions, ${ }^{24}$ or when legality cannot be used to justify the assassination of a human being. ${ }^{25}$ In order to resolve the interruption difference makes to naturalized regulatory routines, translation is often invoked as a practice with the capacity to articulate those differences. But those differences, contrary to what might seem intuitive, are not completely explicit or pre-given. The act of translation, we argue, is what incites the elaboration and expansion of difference in terms specific enough for the translation process to perform its productive change. Once broadly identified, the concrete and specific contents of difference have to be elaborated, identified, and recognized through the actual process of translation of specific regulatory issues. Thus, rather than taking translation as a response to a pre-given reality, a more dynamic understanding of translation assumes that, in order for two or more regimes to be recognized as different enough to warrant translation their concrete differences need to be specifically defined. [End Page 8] Without translation acts, certain differences remain as dormant, unarticulated background.

In this sense, translation has a performative dimension to it. ${ }^{26}$ While articulating distinct dimensions of social life, it instantiates, specifies, and concretizes the difference that it claims to resolve. Studying acts of translation or using translation as an analytic while attending to its performative dimension poses important empirical questions about the concrete differences in need of articulation. In other words, thinking of translation from this perspective requires social analysts to account and carefully identify the differences at stake and their specific 
configurations. The papers in this collection carefully demonstrate how such differences are specified by way of defining financial benefit sharing, national borders, regulatory objectives, affective foundations of legal metaphysics, reputational concerns of liberal professionals, and genres of communication.

In charting the specificity of difference through their cases, the contributing authors also engage with the productivities of translation as an unstable concept. The papers offer lively interdisciplinary attempts to articulate that instability without unleashing laudatory manifestoes for the use of translation or cynical denunciations of its arbitrariness. The collection seeks a different objective. It attempts to work through and spend time with a concept that seems to be fraught with difficulties. It also responds to its proliferation as a means of explaining legal and political work for diverse actors who engage with regulatory regimes within the legal profession but also outside of lawyerly and judicial traditions. This conceptual and practical multiplication of translation processes and of translators requires the authors to be cautious about their analytic engagement. The papers attempt to trace the excesses of translation processes and mechanisms, those things that remain beyond the reach of translation efforts, while also paying attention to their efficacy as means to enable the circulation and homogenization of regulatory regimes.

This conscious engagement with a fraught concept leads to a particular attentiveness to its historical and cultural entanglements, which in turn reveal the iterative character with which translation as a practice and an analytic tool is carried out in contexts of (democratic) [End Page 9] legal and political practice. Seyla Benhabib describes iteration as "complex processes of public argument, deliberation, and exchange through which universalist rights claims and principles are contested and contextualized, invoked and revoked, posited and positioned."27 Translation of regulatory frameworks is also iterative, although along different lines. It entails recurring public consultations, expert assessments, and international coordination among corporate, scientific, and technical actors involved in the specification of translated regulatory norms. Formulated, revised, and modified in conversation with powerful economic and political interests, the iterative character of regulatory translations is embodied in the technicality of their contents. As a result, ruling through regulatory architectures recursively confronts different scales of governance, generates numerous encounters between varied conceptual worlds, excludes some actors, and produces a flurry of regulatory hybrids. ${ }^{28}$ But, as the papers ahead show, this iterative character of translation goes beyond the status quo of liberal democracy and can be traced, with formal variations, from colonial times ${ }^{29}$ all the way to imaginations of the future. $^{30}$

While translation is often imagined as a linear relation —often as a dyad mediated by a translation act - the papers in this volume, thanks to their concern with historic specificity, bring to light how translation processes unleash multiple semiotic and ontological entanglements and effects. Explained in terms of multi-directionality and multiplication, the increase in the domains mediated through translation acts results in significant qualitative changes to the kinds of insights we derive from following the translation process. The encounter of multiple realms cannot be mechanically elucidated as to allow accurate predictions of its ultimate effects. While certain realms or elements retain their form through the process of translation, others are transformed to the extent that their ultimate formation seems to have little in common with the text, act, or norm originally translated. These multiple combinatorial possibilities cannot be completely 
anticipated, and make objectionable any reductive analysis that privileges dyadic relations between national [End Page 10] legal traditions, regulatory languages, or juridical actors. Rather than simply tracing the movement of a regulatory concept from point $\mathrm{A}$ to point $\mathrm{B}$, these combinatorial possibilities yield highly unstable processes and require social commentators to pose questions about what is really articulated with translation. Furthermore, those combinations can even change the conceptualization of translation from a mechanical transformation to a generative process with consequences that exceed the mere standardizing of regulations in a globalized world. Thus, without the certainty of merely performing a critique of the reductive character of translation, the papers in this collection show how multiple social fields saturated with power, politics, and history are articulated and transformed into regulatory arrangements that translation can never fully standardize. To trace those productivities, we offer four entry points into how the papers tame the complex translation processes they trace.

\section{Conceptual Points of Entry to Regulatory Translations}

\section{A. Time}

As many of the papers in the collection show, the process of translation revealed concrete by an acute consideration of time. Attending to the duration of social life reveals how translation practices relate texts or events preceding the moment of translation with those yet to comeexpected and unexpected - and how that association tends to be iterative. In this regard, attention to temporality in the translation of regulation powerfully challenges any attempt for fixity in the meaning of the law. Time makes necessary a consideration of the ambiguities, polyphonies, and unexpected effects that the law and regulatory frameworks unleash in the world. The contribution that these papers make in relation to the act of translation in time is to go beyond the diagnostic move of saying that, in real time, the law is multiple-something that seems to be widely accepted - to show the multiple temporalities in which it exists and which it produces.

Iza Hussin, for example, powerfully shows how it is the material and bodily circulation of people across what Sousa Santos calls the "symbolic cartography of law"31 of the Indian Ocean that makes possible a historic "translation" of constitutional texts in late nineteenth century Johor, a sovereign state at the southern tip of the Malay Peninsula. The [End Page 11] historic outcome of this process of translation is the birth of a sovereign state under a constitutional text recognizable to the West. The material and geographic circulation of ideas, and bodies, is a symbolic cartography defined by iterative movements that culminate with the adoption of the Malay Constitution. The Sultan of Johor takes that symbolic cartography and translates it into a constitution based on multiple sources and authors that, as Hussin notes, are "always and already texts in translation." 32 Pushing recent attention in law and society scholarship to legal geographies forward, Hussin shows that it is not merely circulation through space, but the effect of circulation in time, with its iterational quality, that allows certain differences to be conflated and others to be re-invented and, in effect, makes the process of translation one that depends on "ambiguity, misreading, and dissonance.",33

While Hussin's paper shows the way in which translation operates through ongoing temporality, Jothie Rajah's paper offers a view on how translation performs a cut in mythical time, a moment 
of break, through Barack Obama's presidential address on the killing of Osama bin Laden in 2011. Rendering legal legitimacy in a new voice, the speech, Rajah argues, decouples law and justice, inaugurating a new era for the legitimacy of law in the United States. ${ }^{34}$ This post 9/11 legal and regulatory epoch is possible because, throughout the President's speech, a point of origin, a time zero, is created. The break, and hence difference, between history before and after the killing of Osama bin Laden is articulated through the affective properties of the speech and its mythical significance for law. Thus, by tracing the ways in which authority, legitimacy, and law are translated into new circumstances - those of the post 9/11 world-Rajah shows how, in its symbolic and world-making dimensions, the law punctuates or breaks time. Moreover, this translation creates an origin myth where legal notions of authority and justice are decoupled through an affective invocation of legitimacy. Time, for Rajah, is turned inside out through a new origin myth enacted by the monarchic symbolism of the material and physical organization of President Obama's speech and its capacity to translate the horror of revenge killing into a nationalist regulatory space.

In Umut Türem's analysis of the translation of competition laws by Turkish regulators, we do not find a traumatic break in the flow of time, but to the contrary, a more seamless intergenerational replenishment of [End Page 12] state technocrats, and with them, a replenishment of rationalities for the work competition laws are supposed to perform in society. Documenting how the "rate of replacement" of the bureaucratic body, and its economic ideology, has had critical effects on the translation of competition regimes into the Turkish context, Türem highlights how the purpose of the first generation of competition laws in the rapidly neoliberalizing Turkey of the early 1990s was replaced with second-generation ideologies of efficiency and aggregate welfare. ${ }^{35}$ Economists employed by the regulatory authority saw themselves as responsible for keeping the regulatory regime up to date with history, or at least, with history as they imagined it. As a result, we see a steady distancing of these regulators' intellectual orientations from an objective of protecting consumers to a goal of securing appropriate conditions for the maximization of wealth, a vague goal that tends to protect powerful interests at the expense of citizens. Translation of competition laws across borders, from European Community countries to Turkey, is substituted with translation of competition scholarship from the United States to Turkey. This shift takes place in a seemingly narrow sliver of time but is, in fact, couched in a deeper political economic shift. The replacement of Europe by the United States as the spring of state-making expertise in the wake of the Second World War translates into a shift from "social market economy" to "welfare economics" as the guiding logic of competition policies in Turkey. Pace and rhythm of regulatory translations are entangled with broader temporal dynamics of global political economy.

Andrea Ballestero's paper zooms into a different time scale. She argues that in the moment of deciding how to transform human rights obligations into concrete regulatory measurements and performance indicators in Costa Rica, a micro semiotic history is unleashed. ${ }^{36}$ These regulatory measurements, in the form of percentages, spark a past and a future in a time scale that is not fully determined by individuals or structural processes. This past and future are determined in relation to training activities for NGOs and as a function of the consumption practices of Costa Rican households during a calendar year. The process of translation, addressed in the article as both a "native" practice and an analytic category, reveals the productivity and expansive effects of translation as a set of semiotic practices. Here, the human right to water, as defined by the 
United Nations, acquires a new afterlife that [End Page 13] envelops actors and institutional settings that are seldom anticipated by international lawyers. This afterlife involves, in one case, NGOs devoted to producing indicators about their own knowledge of human rights, and in the other case, economic regulators setting the price of water to secure its affordability and its character as a human right. The act of translation as performed through highly technical numerical operations constitutes a before and after that connects unexpected locations and disciplinary traditions. In measuring indicators before and after training, NGOs give human rights an afterlife that reveals how the law is a continuous social practice and not only a circumscribed presence. In calculating a price that keeps water affordable, regulators connect human rights to ongoing acts of exchange and consumption across households spreading the reach of human rights into new domains.

Drawing on science and technology studies, Kregg Hetherington uses time as a methodological resource to bring to our attention three moments in which regulatory frameworks perform "ontological translations" that multiply soybeans, rather than simplifying and binding them. Hetherington argues that agricultural regulations have the effect of making soybeans excessiveto the degree that their existence drags complex assemblages of people, objects and legal technologies that enlarge and diversify the seemingly humble beans. ${ }^{37}$ Hetherington uses three moments of translation to question the notion of a "framework" as it is often used in socio-legal scholarship. His juxtaposition of three moments in which regulation expands the ontology of the bean highlights the need for considering regulatory practices in time scales that go beyond the micro and the macro. A decade, in the case of Paraguay, reveals the geometrical transformation and addition of actors, laws, political conflicts, and material characteristics of soybeans. This growth had very real political consequences in Paraguay, including the overthrow of a democratically elected President. As Hetherington shows, these expansive ontologies are not merely desirable celebrations of multiplicity and difference, but translations through which the very foundations of political, legal, and natural arrangements can be transgressed and reinvented, sometimes to violent and disruptive effects. [End Page 14]

\section{B. Technicalities}

In the past decade, socio-legal scholars have started looking at the technicalities of law-making as sources for theoretical reflection. ${ }^{38}$ Such technicalities have often occupied the attention of practitioners both as opportunities for innovation and as limitations to their discretion. The technicalities of the law and regulation, as far as they can be reinvented, offer opportunities to understand change and transformation. To the extent that they are assumed to be immutable, they can reinforce dominant ideologies and taken-for-granted ontologies. In either case, the process of translation, a process that is intrinsically about change, turns technicalities into fascinating junctures to map the scope of reinvention and reproduction.

Investigating the means by which increasingly transnational regulatory orders allocate value, Laura Foster suggests that it is not mere translation, but translation as a political process that needs to be addressed when studying intellectual property regimes. Proposing translation as a sociolegal methodology to examine the uses and effects of patents and benefit-sharing agreements, Foster emphasizes the role of responsibility in what she terms critical cultural translation. ${ }^{39}$ This type of translation captures the "hierarchies of knowledge, power, and 
difference" that undergird the regulatory orders constantly proliferating and associating capitalist ventures with indigenous knowledges, such as the knowledge held by South African communities about Hoodia gordonii (Hoodia). ${ }^{40}$ When principles of benefit sharing contained in the United Nations Convention on Biological Diversity are "technically" translated into the South African Biodiversity Act, two options open up. One would be to treat the process as a mere technical transplantation and reduce it to the language of legal texts. Another option, the one Foster argues for, requires paying attention to the historical embeddedness, violence, and hierarchies of power entangled in devising the technicalities of a national regulatory regime. By taking the second approach, it is possible to make explicit the distribution of responsibility that happens in translation. In South Africa, patent law does not exist [End Page 15] as a neutral technical innovation; it is embedded in long processes of bioprospecting, scientific discovery, and colonialism that cannot be bracketed. Foster's argument is that through a method of critical cultural translation, such violent histories become apparent and, in consequence, socio-legal analysis can offer insights that, while focusing on techno-legal innovation, do not obscure issues of power and justice. ${ }^{41}$

Yasmine Chahed's article on accounting standards in the United Kingdom also engages with the technicalities of regulation and examines how novel tools are adopted and modified. Specifically, she reveals how innovation in accounting standards occurs and how those changes can destabilize deeply entrenched preferences for quantitative, and not qualitative, data in the imagination of the accounting world. Chahed studies the inclusion of "narrative reporting" into the British Accounting Standards and suggests that such inclusion is made possible thanks to a multidirectional process of translation whereby professional trajectories, institutional structures, and the very role of accounting in society are negotiated. ${ }^{42}$ In the United Kingdom, the inclusion of narrative reporting to address the future as imagined by managers produces a new a sense of legitimacy for a different kind of technical instrument that, according to conservative views, lacks the objectivity that numbers are believed to convey. Chahed highlights how these technical innovations, if placed only within the purview of regulatory bodies, might seem more radical than they really are. By highlighting, for example, how discourses of "relevance lost" and preoccupations with the expansion of cross national standards encounter responses across institutional settings, Chahed demystifies innovation and shows its embeddedness in messy dynamics of push and pull among diverse actors and bodies. ${ }^{43}$ Thus, translation, as a multidirectional process, prevents a celebratory rhetoric of "virgin births" of new technical standards and reveals constellations of ongoing discussions, historical legacies, and futureoriented desires.

Türem's article, similarly to Foster's, takes the importation of a "legal technology" to a context where it hitherto did not exist. Competition laws did not constitute a separate legal domain in Turkey until 1994, the year when the Turkish parliament passed this body of laws. Türem shows that competition laws have not been ordinary laws commanding and regulating conduct. Rather, what comes along with these laws is a set of economic technologies as to how to conceptualize [End Page 16] and intervene in the economy. Narrating the complicated process of importing and appropriating such technicalities, Türem shows how these technical measures are intimately related to the broader waves of political economy of the country into which they are planted. ${ }^{44}$ Echoing Chahed's findings, Türem shows how the "work" of law cannot be adequately analyzed by solely looking at legal cases on competition violations or administrative decisions issued by 
the Turkish Competition Authority. He examines the "expertise theses" written by the Competition Authority's career personnel as a way to grasp the implications of the technical apparatus that accompanies such laws. ${ }^{45}$

\section{Layers (and Spaces)}

Technicalities and their proliferation offer a window through which the politics of institutional entrepreneurship and legal engineering can be analyzed. What is interesting in the current phase of globalization is that such institutional engineering and regulatory constructions take place at a number of different geographical scales that significantly shake the uniqueness of the nationstate as the natural container of economy, law, and politics. ${ }^{46}$ Furthermore, such multiplication of geographical scales of rulemaking in the global political economy is accompanied by the multiplication of normative scales of meaning, which do not always neatly correspond to the geopolitical scales. ${ }^{47}$ The perceived incongruities between normative and spatial scales, and the efforts to erase the "friction" 48 between norm and reality, are sites where the politics of global regulatory emergences can be fruitfully observed.

Yet, what is novel about these constantly emerging frameworks is their increasing density and experimental nature as well as the reflexive outlook of the social actors promoting them. Not only are regulatory schemas presented as flexible and fluid, they are often generated in an effort to address the concomitant problems generated by the speed and density of interconnectedness across the globe, even if only temporally. These "problems" of interconnectedness are instances [End Page 17] of denaturalized difference that translators attempt to tame through the invocation of geographic maps of legal jurisdictions. Here we find that difference is commonly explained by way of spatial parameters such as national and jurisdictional borders and scales. But, as Mariana Valverde notes, it is not enough to think of space in cartographic or geographic terms. For her, space is a set of practices, an ideal, maybe a kind of place, but all of these are the outcome of specific technologies of which legal ones are especially salient. ${ }^{49}$ In studying regulatory translations, rather than assuming a taken-for-granted global cartography characterized by the two-dimensional maps on which geopolitics, and by extension globalization, often rely, the spatial dimension of the papers in this collection is better understood by examining different layers. Questioning the self-evidence of the purely geographic, layers can be jurisdictional, as in the challenges EU regulations pose to national legal systems, and they can be epistemological, as in the cross-citation practices of courts. While having a spatial significance, these layers do not match representations of the flow of regulatory instruments through flat cartographies of national borders and languages. Layers are better imagined by thinking of three-dimensional spaces where different strata combine and shape each other in oblique ways. ${ }^{50}$

Katharina Mangold's article powerfully excavates the significance of layers of institutional history and past translations by following the development of "representative environmental action" in the German context. Mangold shows how the "individual public right" doctrine in Germany, which dates back to the nineteenth century, has conditioned the current public interest standing regime for German environmental NGOs. Mangold analyzes, in careful detail, the various ways the current international and regional (i.e., European Union) regulatory frames for public environmental action exist side by side with the historically peculiar public individual right doctrine in Germany. She concludes that in the process of translation from above, that is 
from regional or international levels to the national level, national peculiarities persist, creating multiple and enmeshed layers of institutional and legal meanings and practices. ${ }^{51}$ Such layering is further conditioned according to the hierarchies and power relations within a given national legal field. Mangold's article suggests that the past, and previous institutional and legal landscapes, are always present and significantly [End Page 18] shape the ways current legal and regulatory translations take place. In this manner, geographical and jurisdictional layers are compounded with temporal ones to reveal the incompleteness of the standardizing of difference that translations attempt to enact.

Wiener and Liste's piece inquires into the formation of a "global community of courts" and reaches a broadly similar conclusion, albeit in a much different context. ${ }^{52}$ The authors test the influential thesis by Anne-Marie Slaughter that an increased level of connectedness, and more specifically cross-referencing, between judges of different countries points to the formation of a "global community of courts." exist as such and that the imagined globality of the legal community that Slaughter asserts is deeply fragmented and semiotically disconnected. Institutional and cultural histories are significant in finding patterns in this fragmented globality; however, this is where the authors come close to Mangold's argument. They suggest that "regional communities, such as the Commonwealth and the European Union, provide a decisive common ground and thence the more important normative guidance for court judges. ${ }^{, 54}$ Historical practices of previous regional institutionalizations and cultural commonalities leave their mark on the emerging global field of law and matter for practices of cross-referencing between judges of different countries. These translations render any cross-referencing or cross-fertilization between judges in different countries an immanent practice against backgrounds of stacked cultural meanings and institutional practices. Instead of thinking of cross-referencing as the movement of ideas through geographic circuits, they are epistemic practices and historical movements that result in a sedimented institutional history that is dense and better understood as stratigraphic.

\section{Politics/Ethics}

Reading regulatory movements through the lens of translation opens numerous analytic possibilities. Time, technicalities, and layers are promising points of entry for this endeavor. They bring us closer to the everyday work that legal actors perform to create and move [End Page 19] regulatory regimes. Once we venture to examine the intended and unintended consequences of these translations, the question of politics/ethics becomes inescapable. To what effect do people engage in sophisticated, generative, and violent translation efforts? We address the ethics question separately because of how it places us at the border of the empirical and the normative. While the above categories all pointed to certain qualities of regulatory translations, the ethics category is slightly different.

A common definition states that "[e]thics ... is the name [philosophers] give to philosophical reflection on morality." " B5 from another point of view we can think of ethics as the "reasoning abilities [of humans] to justify our behavior to other members of our group." The myriad regulatory experiments that constitute our world constantly demand justifications of rules and norms to new communities of belonging organized around values and interests that often transcend the liberal definition of the nation-state. These circumstances, Singer argues, need "to 
be reflected in all levels of our thought, and especially in our thinking about ethics." ${ }^{\circ 7}$ As part of this necessary updating, Western political theory shifted from questions of redistribution to issues of recognition initially in the $1980 \mathrm{~s},{ }^{58}$ and later, in the 1990s, "political philosophers have more radically confronted the repercussions of a multi-centered, globalizing world ... that challenged the parameters of democratic theory." politics require us to explicitly reflect on the subjects and communities that are constituted or put under erasure as a consequence of globalized regulatory frameworks.

Framing the question as one of ethics is significant insofar as regulation is championed by some as a legal technology less burdened by the weighty political value of justice seemingly undergirding "the law." We have already pointed out the potential violence embedded in regulatory translations. Explicitly addressing the politics and ethics of the technical is key to making that violence visible and speakable, and for bringing questions of justice back into the picture. As the papers in [End Page 20] this volume show, regulatory translations not only emerge and develop in politically constituted environments, but are also constitutive of politics. They enable or foreclose alternatives that are seldom mere extensions of earlier political paths or configurations. As Susan Gal points out, translation is a "multilayered phenomenon, consisting of specific social relations and multiple semiotic processes that mediate the movement of 'ideas,' creating conditions of possibility for political [and legal] action." ${ }^{, 60}$ Moments of translation, in other words, can reveal political potentialities and bring them into the domain of the actual. To the extent that regulatory translations reinvent or actualize meaning, they also have the potential of reinventing subjectivity and community or precluding formations that challenge dominant structures of power, meaning, and capital. Jothie Rajah's article, for example, shows how the killing subject becomes sanitized via the invention of new political myths and affects that are capable of translating revenge into nationalism. Laura Foster addresses the ethics of "benefits" in the technical language of intellectual property law where the property owner is a particular postcolonial subject that stands in opposition to the subject that bears traditional knowledge. Iza Hussin shows that by adopting a constitution, the Sultan of Johor enabled a recognizable modern subject position for himself, thereby opening up a space of resistance against a potential imperial threat by Britain. Thanks to the polyphony and the inherent ambiguity in laws and their translation, such legal reform proved to be a malleable resource to tap into for future rulers of Johor.

These political and ethical effects of translation also reach notions of community. Regulatory translations occurring at the interstices of the domestic and the international levels, as well as those designed to partition communities into public and private spheres, shape communities and run the risk of engendering "democracy deficits." 61 The engineering of regulatory models that are sufficiently flexible to move between private and public or national and global domains might carry significant adverse implications for citizens, that community of people who are supposed to have a political say-however limited - about the collective future, but whose power is severely crippled in the in-between [End Page 21] zones of globalization. ${ }^{62}$ Hetherington's piece exemplifies how the expansion of community to consider the interests of extraterritorial players in Paraguay results in political resistance and violence against the unprivileged. In practices of inter-court cross-referencing, as Wiener and Liste argue, community depends on a shared semiotic commons. Its absence, the inexistence of a system of shared legal 
meanings, breaks the possibility of any substantive community among judges who, nevertheless, might have common citational patterns.

But not all novel regulatory arrangements lead to democratic deficits in the definition of subject and community. In fact, out of the globalized and somewhat new regulatory architecture of the nation state new possibilities for more democratic forms of rule, participation, and decisionmaking can emerge. These possibilities have the potential for amplification, ${ }^{63}$ and can lead to progressive political engagements that challenge, if only partially, political and economic orthodoxies. Without reference to radical transformation, Ballestero's article shows how novel regulatory tools and methods can be appropriated, and in fact created, by concerned citizens and public officials to overcome free market orthodoxy in the provision of drinking water to households. Chahed argues that the very act of standard innovation in the UK is substantiated by networked processes of translation that radically expand the accounting community beyond the limited collectives that claim authorship of accounting standards innovations. What is possible to view in these instances is a mode of experimentation with the potential of producing novel or slightly changed forms of community beyond national borders and public-private classifications. Such challenges can potentially involve cross-border and grassroots movements and mobilize the language of legality and justice to create [End Page 22] alternative communities of solidarity. ${ }^{64}$ By amplifying the community and subject-making effects of translation, scholars can focus not only on the 'permeability' of territorial borders, but on whether and how evolving notions of globality might open space for a political theory of different subjects and communities. ${ }^{65}$ This, in turn, makes ethics a central concern for those interested in exploring regulatory translations.

\section{Moving on with Translation(s)}

Amid the different forms of epistemic and material violence that we encounter in the world, the instrumentality of regulatory regimes comes into question through translation. Querying the apparent efficiency with which regulatory tools facilitate the constitution of global circuits of people, capital, and ideas, translation can highlight the unexpected inability of regulatory translations to completely stabilize difference. Unlike the assumptions on which previous critiques of the act of translation relied; that is, the nonexistence of a legitimate original or translation's attempt to homogenize difference, the papers in this issue show that translation has taken, today, a more contradictory role. As a practical realm and as an analytic device, translation helps deal with some of the paradoxes between global/local, national/transnational, affective/material, and mythical/technical that characterize law-related struggles at the regulatory level. It does so because translation simultaneously embodies the ambiguity and intended fixity of law-related processes. Translation helps temporarily fix certain concepts and elements while recognizing their fluidity. It reminds us of the epistemic violence that meaning making always performs while allowing certain pragmatic arrangements to unfold. It highlights the multiplicity and difference that the world consists of. It also attempts to homogenize and standardize difference and, inevitably, it fails to do so, revealing to all those involved in the translation process the impossibility of creating seamless and frictionless regulatory circuits for capital and power. This capacity to confront, tame, and exacerbate these [End Page 23] contradictory 
threads makes translation a concept that continues to hold analytic purchase despite its long genealogies in the humanities, social sciences, and science and technology studies. As an analytic category, translation prevents us from producing simplistic accounts and keeps critical analysis in an unstable space that forces us to leave no presupposition unexplored. Working with a concept that is simultaneously productive and problematic, we argue, leads to a productive exploration of the regulatory era that scholars have diagnosed.

We consider this special issue a contribution to an effort to think about the complex phenomenon of regulatory movements by using translation as an analytic frame. As we already noted, it is also possible to think with translation not just as an analytic, but also as an object of analysis: an ongoing process unfolding in the world and in need of analytic attention. Either way, we hope this exploratory introduction to regulatory translations speaks to the curiosity of scholars and practitioners interested in the ongoing transformations of regulatory regimes, legalities, and forms of globalization in which we participate.

As the reader will note, the papers in this collection come from various academic backgrounds, ranging from law to anthropology, or science and technology studies to accounting. As such, we expect the articles to raise sufficient interest in our readers to engage in translations of their own. The readers are invited to leave their disciplinary home bases and venture into different zones and methods of knowledge production. Legal scholars would likely need to exercise their skills in sociological thinking and anthropological analyses. Social scientists, in general, would need to focus their attention to the details of legal history. There is also quite a bit of economics in most of the papers, some referring to it explicitly, others implicitly. What we hope to achieve in facilitating such transborder explorations is a contribution to understanding legal and regulatory phenomena and their circulation in a post/trans-disciplinary space.

These transborder explorations were initially made possible by the joint efforts of three different institutions. We organized the Regulatory Translations workshop in Istanbul with the support of the Indiana University Maurer School of Law, Rice University's School of Social Science and Anthropology Department, and Boğaziçi University's Atatürk Institute for Modern Turkish History and the Boğaziçi University Foundation (BUVAK). The process of organizing the workshop was itself a crash course in institutional translation, but, for the great end result, we wish to thank these institutions.

There are, of course, a number of individuals to whom we would like to extend our thanks. Alfred Aman, editor of the Indiana Journal of [End Page 24] Global Legal Studies and Professor of Law at Indiana University, supported the project from the very beginning and helped facilitate the publishing of the articles in this special issue. Without his contributions, this project would not have materialized. Participants in the workshop, by presenting a paper or joining a roundtable, deserve special thanks. It is thanks to the collegiality and generous engagement with each other's ideas that we have been able to put forward an issue that tackles the complicated question of what it means to think through translation in the twenty-first century. We would like to specially thank Robert Werth, Anjie Rosga, and Peer Zumbansen for their thought-provoking contributions to the workshop. Similarly, thanks also go to Yavuz Mavioğlu and Tuna Kuyucu for being part of the conversation in the workshop. Nazife Kosukoğlu, Ekin Mahmuzlu, and Çiğdem Oğuz, graduate students at the Atatürk Institute for Modern Turkish History, helped us with the logistics and organization during the workshops, and they, too, 
deserve heartfelt thanks. Colin Ford, Shirin Lakhani, Adam Somberg, and Yoonjin Min, students from Rice University, enriched the conversation by often pointing at some of our own unexamined assumptions. Finally we would like to thank Jia $\mathrm{Li}$ and the team of student editors of the Indiana Journal of Global Legal Studies for their skillful editing and patience in engaging with the diverse scholarly traditions represented here. Finally, a hearty thank you to all of the contributors for their collegiality, humor and generosity. [End Page 25]

\footnotetext{
${ }^{1}$ The name is a pseudonym.

${ }^{2}$ David Levi-Faur \& Jacint Jordana, The Making of a New Regulatory Order, 598 Annals Am . Acad . Pol . \& Soc . Sci . 6, 6 (2005).

${ }^{3} I d$. (emphasis omitted).

${ }_{5}^{4}$ Robert Baldwin et al ., Understanding Regulation : Theory, Strategy, and Practice 2 (2d ed. 2012).

${ }^{5} I d$. at 1 . We have conducted a very simple search to verify our (and others') observation that regulation as a topic of academic interest has become more prominent. We searched the Social Science Citation Index from 1956 onwards to see the number of refereed journal articles that contain the word "regulation" in their title, and that contain "law" as their "topic." The results are telling. Between 1956 and 1991 (inclusive), our search yielded 211 results. Between 1992 and 2002 (inclusive), the search yielded 286 results, more, in this decade, than what was out there in the previous three and a half decades. More to the point, between 2003 and 2013 (inclusive) the search yielded 814 results, close to a threefold increase over the previous decade. This only includes the social science citation indexed articles and most likely the numbers in law journals are much higher. In any case, the results are self-explanatory: regulation has become a solid point of academic interest.

${ }^{6}$ Bronwen Morgan \& Karen Yeung, An Introduction to Law and Regulation 3 (2007).

${ }^{7}$ See generally David Harvey, The Condition of Postmodernity (1990).

${ }^{8}$ See generally Zygmunt Bauman, Liquid Modernity (2000).

${ }^{9}$ See generally Luc Boltanski \& Eve Chiapello, The New Spirit of Capitalism (2005).

${ }^{10}$ See Kanishka Jayasuriya, Reconstituting the Global Liberal Order : Legitimacy and Regulation 71-82 (2005); Rodney Bruce Hall \& Thomas J. Biersteker, The Emergence of Private Authority in the International System, in The Emergence of Private Authority in Global Governance 3 (Rodney Bruce Hall \& Thomas J. Biersteker eds., 2002).

11 "Elective affinity" or affinities is a construct used initially by the sociologist Max Weber to go beyond mechanistic and causal tendencies in explaining social phenomena. In this case, rather than suggesting that capitalism or neoliberalism has led to the rise of regulation, it helps us pose the question as one of mutual structuration feeding off one another. See Richard Herbert Howe, Max Weber's Elective Affinities: Sociology Within the Bounds of Pure Reason, 84 Am . J. Soc . 366, 366 (1978), for a detailed analysis of the origins and the use of the concept by Weber.

12 Jayasuriya, supra note 10 , at 95.

${ }^{13}$ Anne -Marie Slaughter, A New World Order 5 (2004)

${ }^{14}$ Id. at 4.

${ }^{15} \mathrm{Id}$. at 5 .

${ }^{16}$ For a discussion of the law and development movement, see generally Law and Development and the Global Discourses of Legal Transfers (John Gillespie \& Pip Nicholson eds., 2012); The New Law and Economic Development (David M. Trubek \& Alvaro Santos eds., 2006); David M. Trubek \& Marc Galanter, Scholars in Self-
} 
Estrangement: Some Reflections on the Crisis in Law and Development Studies in the United States, 1974 Wis . L. Rev . 1062.

${ }^{17}$ See generally Alan Watson, Legal Transplants : An Approach to Comparative Law (2d ed. 1993).

${ }^{18}$ See generally Teemu Ruskola, Legal Orientalism: China, the United States, and Modern Law (2013); Rethinking the Masters of Comparative Law (Annelise Riles ed., 2001).

${ }^{19}$ See David Kennedy, The Dark Sides of Virtue: Reassessing International Humanitarianism , at xvi (2004).

${ }^{20}$ See generally Sally Engle Merry, Anthropology and International Law, 35 Ann . Rev. Anthropology 99 (2006);

Sally Engle Merry, Transnational Human Rights and Local Activism: Mapping the Middle, 108 Am .

Anthropologist 38-51 (2006).

${ }^{21}$ See generally Rachel E. Stern, Unpacking Adaptation: The Female Inheritance Movement in Hong Kong, 10

Mobilization 421 (2005).

${ }_{22}$ See, e.g., Bruno Latour, Reassembling the Social: An Introduction to Actor -Network -Theory (2005); Bruno Latour, The Powers of Association, in Power, Action and Belief 264 (John Law ed., 1986).

${ }^{23}$ See, e.g., Jacques Derrida, From Des Tours de Babel, in Difference in Translation 218 (Joseph F. Graham ed., 1985); Jacques Derrida \& Lawrence Venuti, What is a "Relevant" Translation?, 27 Critical Inquiry 174 (2001).

${ }^{24}$ See, e.g., Anna Katharina Mangold, The Persistence of National Peculiarities: Translating Representative Environmental Action from Transnational into German Law, 21 Ind . J. Global Legal Stud. 223 (2014).

${ }^{25}$ See, e.g., Jothie Rajah, Sinister Translations: Law's Authority in a Post-9/11 World, 21 Ind . J. Global Legal Stud. 107 (2014).

${ }^{26}$ For more information about the concept of performativity, see generally Judith Butler, The Psychic Life of Power: Theories in Subjection 63-82 (1997); Michel Callon, What Does It Mean to Say that Economics Is Performative?, in Do Economists Make Markets ? On The Performativity of Economics 311-357 (Donald A. MacKenzie et al. eds., 2007); Rosalind C. Morris, All Made Up: Performance Theory and the New Anthropology of Sex and Gender, 24 Ann . Rev . Anthropology 567 (1995).

${ }^{27}$ Seyla Benhabib, The Rights of Others : Aliens , Residents, and Citizens 179 (2004).

${ }^{28}$ For a thorough documentation of how newly emerging scales of governance produce novel regulatory architectures, see Neil Brenner, New State Spaces: Urban Governance and the Rescaling of Statehood (2004).

${ }^{29}$ See generally Iza Hussin, Misreading and Mobility in Constitutional Texts: A Nineteenth Century Case, 21 Ind . J. Global Legal Stud. 145 (2014).

${ }^{30}$ See generally Yasmine Chahed, Translations in Regulatory Space: The Arenas of Regulatory Innovation in Accounting Standard Setting, 21 Ind. J. Global Legal Stud. 195 (2014).

${ }^{31}$ Boaventura de Sousa Santos, Law: A Map of Misreading. Toward a Postmodern Conception of Law, 14 J.L. \& Soc'y 279, 286 (1987).

${ }^{32}$ Hussin, supra note 29, at 148.

${ }^{33} I d$.

${ }^{34}$ Rajah, supra note 25 , at 111.

${ }^{35}$ See generally Ziya Umut Türem, Competition Law Reform in Turkey: Actors, Networks, Translations, 21 Ind . J. Global Legal Stud . 159 (2014).

${ }^{36}$ Andrea Ballestero, What Is in a Percentage? Calculation as the Poetic Translation of Human Rights, 21 Ind . J. Global Legal Stud . 27, 31 (2014).

${ }^{37}$ Kregg Hetherington, Regular Soybeans: Translation and Framing in the Ontological Politics of a Coup, 21 Ind . J. Global Legal Stud. 55, 57 (2014).

${ }^{38}$ See, e.g., Annelise Riles, A New Agenda for the Cultural Study of Law: Taking on the Technicalities, 53 Buff . L. Rev. 973 (2005); Mariana Valverde, Jurisdiction and Scale: Legal 'Technicalities' as Resources for Theory, 18 SOC. \& Legal Stud. 139 (2009). See also Bruno Latour, The Making of Law : An Ethnography of the Conseil D'etat (Polity Press 2010) (2002).

${ }^{39}$ See generally Laura A. Foster, Critical Cultural Translation: A Socio-Legal Framework for Regulatory Orders, 21 Ind. J. Global Legal Stud. 79 (2014).

${ }^{40} \mathrm{Id}$. at 82.

${ }^{41} I d$. at 79.

${ }^{42}$ See generally Chahed, supra note 30.

${ }^{43} \mathrm{Id}$. at 201-02.

${ }^{44}$ See Türem, supra note 35 , at 167.

${ }^{45} I d$. at 185. 
${ }^{46}$ See generally Neil Brenner, Beyond State-Centrism? Space, Territoriality, and Geographical Scale in Globalization Studies, 28 Theory \& Soc'y 39 (1999).

${ }^{47}$ See generally Nisha Shah, The Territorial Trap of the Territorial Trap: Global Transformation and the Problem of the State's Two Territories, 6 Int'l Pol . Soc . 57 (2012).

${ }^{48}$ See generally Anna Lowenhaupt Tsing, Friction: An Ethnography of Global Connection (2005).

${ }^{49}$ Valverde, supra note 38, at 153.

${ }^{50}$ See generally Stuart Elden, Secure the Volume: Vertical Geopolitics and the Depth of Power, 34 Pol . Geography 35 (2013).

${ }_{52}^{51}$ Mangold, supra note 24, at 260-61.

${ }^{52}$ See generally Antje Wiener \& Philip Liste, Lost Without Translation? Cross-Referencing and a New Global Community of Courts, 21 Ind . J. Global Legal Stud . 263 (2014).

${ }^{53}$ See Anne-Marie Slaughter, A Global Community of Courts, 44 Harv . Int'l L.J. 191 (2003).

${ }^{54}$ Wiener \& Liste, supra note 52, at 296.

${ }^{55}$ Kwame A. Appiah, Thinking it Through: An Introduction to Contemporary Philosophy 178 (2003).

${ }^{56}$ Peter Singer, One World: The Ethics of Globalization 12 (2002).

${ }^{57} \mathrm{Id}$. at 8 .

${ }^{58}$ See generally Nancy Fraser, Rethinking Recognition, 3 New Left Rev. 107 (2000); Charles Taylor, Multiculturalism and "The Politics of Recognition" (1992).

${ }^{59}$ Günter H. Lenz \& Antje Dallmann, Introduction, in Justice, Governance, Cosmopolitanism and the Politics of Difference: Reconfigurations in a Transnational World 5, 5 (Engelbert Habekost, ed. 2007).

${ }^{60}$ Susan Gal, Movements of Feminism: The Circulation of Discourses About Women, in Recognition Struggles and Social Movements 93, 93 (Barbara Hobson ed., 2003).

${ }^{61}$ Alfred C. Aman, Jr ., The Democracy Deficit: Taming Globalization Through Law Reform 1 (2004).

${ }^{62} I d$. at 3. See also Paul R. Verkuil, Outsourcing Sovereignty (2007), for a discussion of such democracy deficit problems, particularly in the context of the United States.

${ }^{63}$ Boaventura de Sousa Santos and César A. Rodríguez-Garavito argue that this "amplification" is an ethical scholarly stance in a world where social science scholarship tends (broadly) to reproduce the orthodoxies and ideologies upon which powerful groups and interests depend. Through an academic practice they call "the sociology of emergence," they argue that scholars need to engage in "critique" by going beyond orthodoxies and pointing to the ways in which subaltern groups form alliances and movements in a process of counter hegemonic globalization, and amplify their voices. This practice of amplification, needless to say, is yet another critical moment of (reflexive) translation work. See Boaventura de Sousa Santos \& César A. Rodríguez-Garavito, Law, Politics and the Subaltern, in Law and Globalization from Below: Towards a Cosmopolitan Legality 1, 17-18 (Boaventura de Sousa Santos \& César A. Rodríguez-Garavito eds., 2005).

${ }^{64}$ See generally Law and Globalization from Below : Towards a Cosmopolitan Legality, supra note 63 (especially César A. Rodríguez-Garavito, Nike's Law: The Anti-Sweatshop Movement, Transnational Corporations, and the Struggle Over International Labor Rights in the Americas, in Law and Globalization from Below : Towards a Cosmopolitan Legality, supra note 63, at 64; de Sousa Santos \& Rodríguez-Garavito, supra note 63, at 1.)

${ }^{65}$ Shah, supra note 47, at 57. This speaks to Peter Singer's calls for a renewed perspective on ethics in the process of globalization. See supra note 57 and accompanying text. 